\title{
C-2 arteriovenous fistula presenting as a pathologic hangman's fracture: case report
}

\author{
Rajeev D. Sen, BA, Carolina Gesteira Benjamin, MD, Howard A. Riina, MD, and \\ Donato Pacione, MD
}

\begin{abstract}
New York University School of Medicine, New York, New York
The authors report on an 81-year-old woman with a pathologic hangman's fracture secondary to a complex arteriovenous fistula (AVF). The patient presented with severe, unremitting neck pain and was found to have fractures bilaterally through the pars interarticularis of C-2 with significant anterior subluxation of C-2 over C-3 along with widening of the left transverse foramen. Due to an abnormally appearing left vertebral artery (VA) on CT angiography, the patient underwent conventional angiography, which revealed a complex AVF stemming from the left VA at the level of C-2 with dilated posterior cervical veins and a large venous varix. Given the radiographic evidence of bone remodeling and the chronicity of the AVF, it is believed that the C-2 vertebra was weakened over time by the pulsatile and compressive force of the vascular malformation eventually leading to fracture with minimal stress. Coil embolization of the AVF was performed followed by surgical fixation of $\mathrm{C}-1$ to $\mathrm{C}-4$. This case highlights the importance of investigating an underlying disease process in patients who present with significant spinal fractures in the absence of trauma.
\end{abstract}

https://thejns.org/doi/abs/10.3171/2016.8.SPINE16351

KEY WORDS hangman's fracture; cervical spine; pathologic; arteriovenous fistula; axis; vascular disorders

A CUTE fractures of the axis (C-2) account for approximately $20 \%$ of cervical spine fractures. ${ }^{7,14} \mathrm{~A}$ hangman's fracture is a unique class of C-2 injury defined by bilateral fractures of the C-2 pars interarticularis. A majority of these fractures are caused by forcible hyperextension of the neck, however, in the absence of obvious trauma, one must consider other more insidious causes of bone injury. While pathologic fractures are generally associated with malignancies or intrinsic bone disease, ${ }^{22}$ we present a case of a pathologic hangman's fracture secondary to a large cervical arteriovenous fistula (AVF). Radiographic and intraoperative findings suggested that the complex AVF originated from the left vertebral artery (VA) and progressively eroded the adjacent C-2 pars allowing for its fracture under minimal stress. The unstable fracture was internally fixed and fused after endovascular embolization of the AVF.

\section{Case Report}

\section{Presentation and Examination}

This 81-year-old woman presented 10 days after an acute onset of upper cervical and suboccipital neck pain.
She was in her usual state of health when she bent over to place a bowl on the ground and noted the sudden onset of neck pain upon lifting her head up. The pain persisted for several days, and she also developed a headache, which caused her to present to the emergency room.

A CT scan of the cervical spine revealed a hangman's fracture with approximately $5 \mathrm{~mm}$ of anterior displacement of the C-2 vertebral body. The left fracture line extended through the transverse foramen and into the $\mathrm{C}-2$ body. The left transverse foramen of C-2 was noted to be widened, and the edges were corticated, suggesting chronicity. The enlarged foramen and fracture were suspicious for a pseudoaneurysm or dissection of the left VA (Fig. 1). The right C-2 pars fracture was proximal to the transverse foramen without corticated edges. A CT angiogram confirmed a large, ectatic left VA that appeared to have eroded the adjacent bone. Cervical MRI showed acute inflammatory signals in the right $\mathrm{C}-2$ fracture line but more chronic changes on the left side (Fig. 2).

Due to the abnormalities seen in the CT angiogram, conventional angiography was conducted to further evaluate the extent of vascular involvement. This unexpectedly

ABBREVIATIONS AVF = arteriovenous fistula; STIR = short T1 inversion recovery; VA = vertebral artery.

SUBMITTED March 24, 2016. ACCEPTED August 31, 2016.

INCLUDE WHEN CITING Published online December 2, 2016; DOI: 10.3171/2016.8.SPINE16351. 

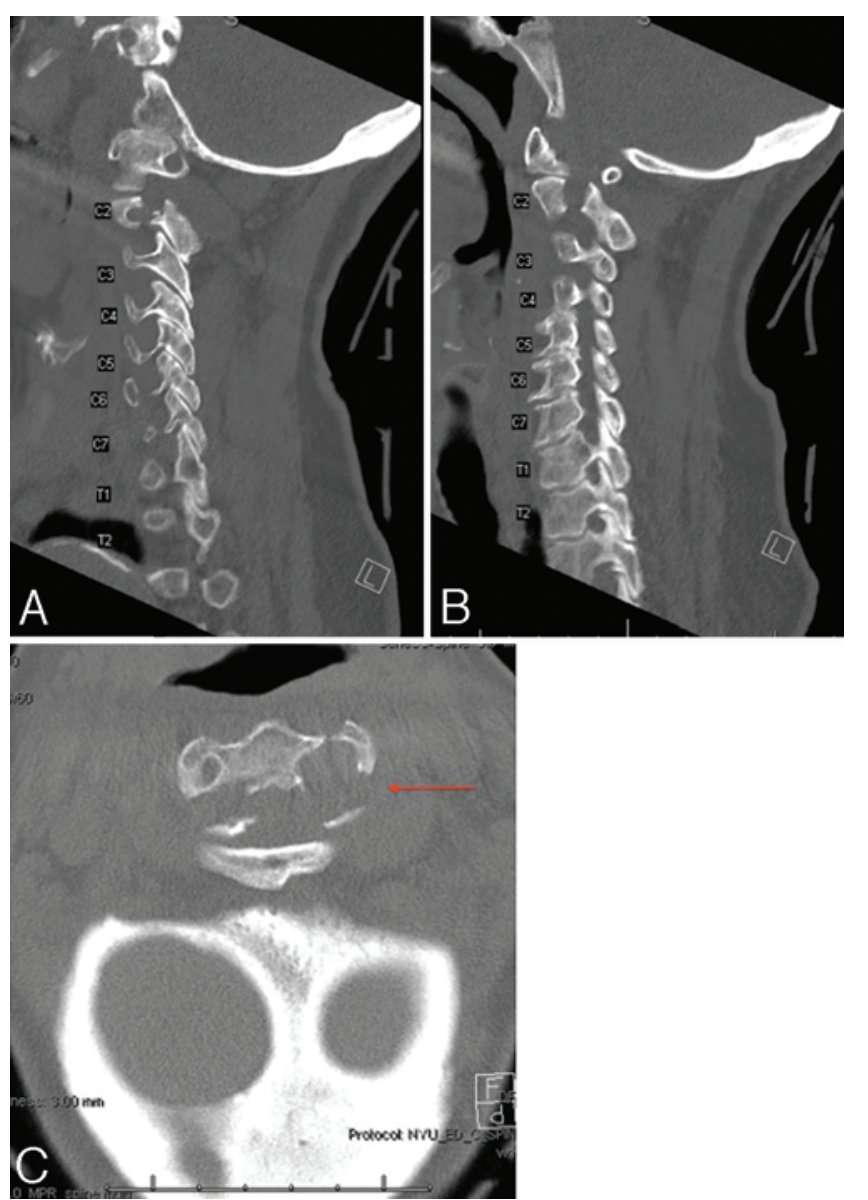

FIG. 1. Preoperative CT scans. A and B: Sagittal images showing a chronic left-sided fracture associated with a large fistulous component (A) and a more acute right-sided fracture (B), as well as significant anterior displacement of C-2. C: Axial image obtained at the C-2 level showing a widened left transverse foramen (arrow) with the fracture line extending through it. Figure is available in color online only.

demonstrated a large AVF from the left VA at the level of $\mathrm{C}-2$ with an associated venous varix and dilation of the posterior venous structures draining into the left jugular vein. There was no flow into the distal left VA or basilar artery, and the posterior circulation was entirely dependent on the right VA (Fig. 3).

\section{Operation}

The combination of $\mathrm{C} 2-3$ disc space disruption, the chronic corticated fracture on the eroded left side, and the patient's age all suggested that the injury would not heal simply with conservative management (Fig. 3). Furthermore, the patient was suffering from debilitating neck pain even with collar immobilization, suggesting instability. Therefore, it was determined that surgical fixation of the C-2 vertebra would be required. However, it was necessary to first obliterate the complex AVF to safely proceed with fixation of the fracture as well as to avoid complications from the fistula itself, such as embolic stroke or hemorrhage.

The patient was taken to the neurological interventional
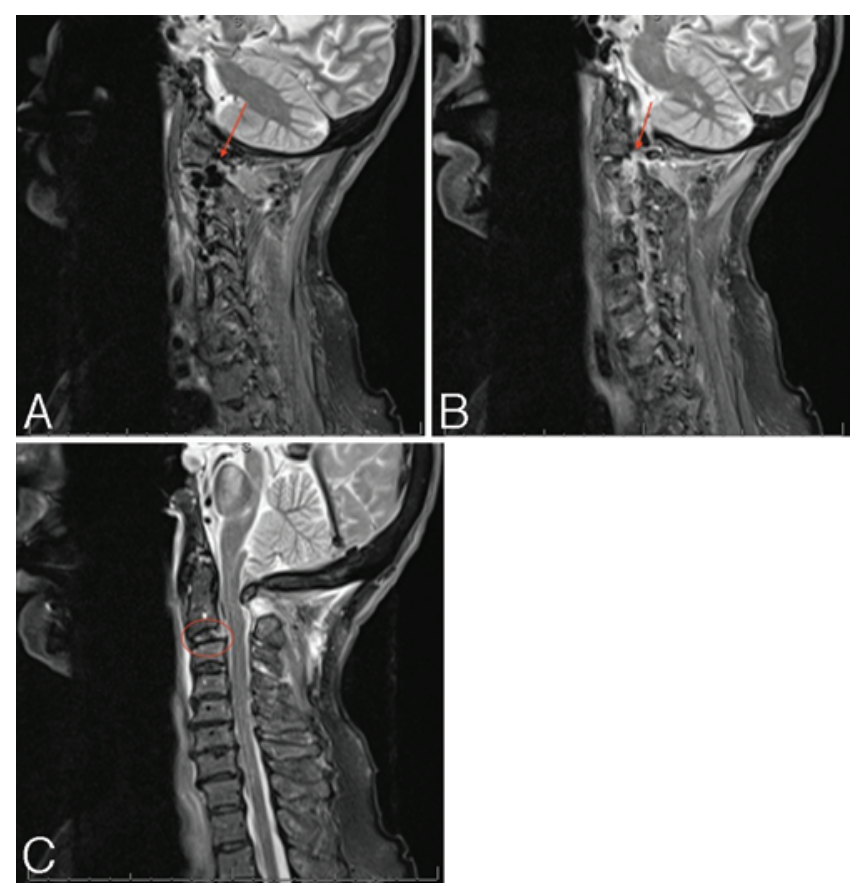

FIG. 2. Preoperative sagittal STIR MR images. A: Left-side fracture showing flow voids associated with the fistulous mass (arrow) without STIR signal indicative of a more chronic process. B: Right-side fracture showing increased STIR signal associated with an acute fracture (arrow). C: STIR image demonstrating C2-3 disc space disruption (circle). Figure is available in color online only.

radiology suite for coil embolization of the AVF. The fistula and left VA were successfully occluded with detachable coils. Post-embolization angiography showed no flow into the AVF, posterior cervical veins, or distal VA (Fig. 3).

Three days after the embolization procedure, the patient underwent $\mathrm{C} 1-4$ posterolateral instrumentation and fusion and C-1 decompressive laminectomy (Fig. 4). The decision for a posterolateral approach was made due to the high rates of dysphagia in the elderly after high anterior cervical procedures. . $^{3,5,12,23}$ The patient was placed in a neutral position and, after opening and releasing the posterior cervical paraspinal musculature, the head holder was readjusted to restore cervical lordosis; however, there was no significant change in the patient's spinal alignment. As a result, it was decided that the patient's neutral position was chronic; given that the primary goal of the procedure was not to adjust her global alignment, as this was not an issue for her prior to the fracture, the neutral cervical position was left unchanged. Additionally, forcing a lordotic contour to the rods would place excessive stress on the lateral mass screws. During dissection of the C1-2 joint, the coil mass associated with the left VA was encountered and dissected to gain access to the lateral mass of $\mathrm{C}-1$. The fractured $\mathrm{C}-2$ vertebra was not included in the fusion mass because of how thin it had become, making the risk of damaging the patient's only patent VA unacceptably high. Instead, fixation was performed above and below the vertebra with placement of bone allograft in the C1-2 joint space and along the posterolateral bone from 


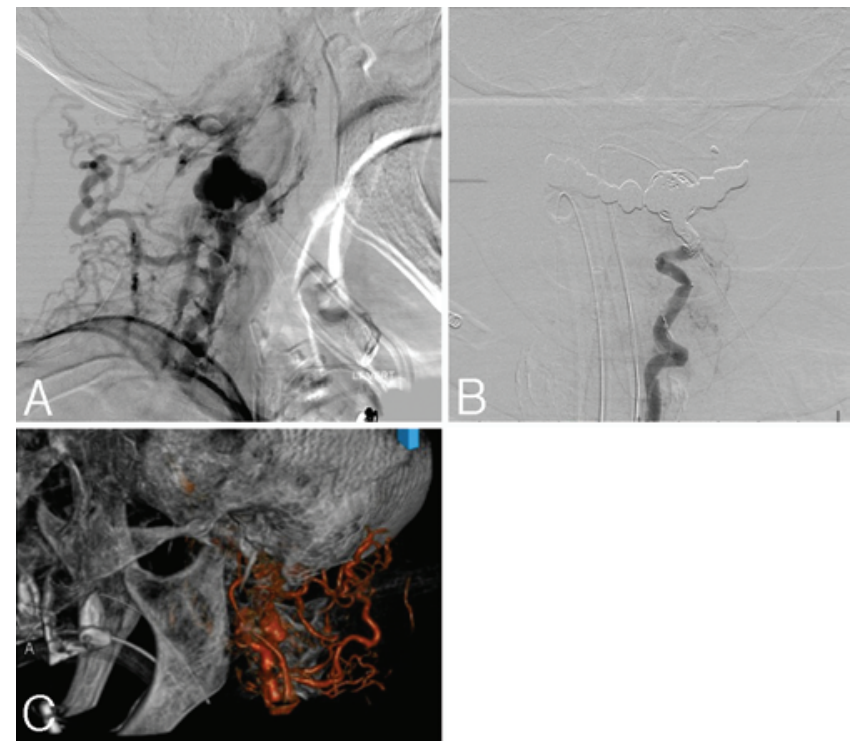

FIG. 3. Angiography. A and C: Pre-embolization image (A) showing dilated posterior cervical veins with a large venous varix and lack of flow into the distal VA and basilar artery, and 3D reconstruction (C) demonstrating the relationship of the AVF to the cervical vertebrae. B: Postembolization image showing complete obliteration of the complex AVF. Figure is available in color online only.

C-2 to C-4. It should be noted that no active fistula bleeding was encountered during the dissection.

\section{Follow-Up}

A 6-month follow-up CT scan showed stable occlusion of the left VA as well as stable instrumentation. Furthermore, the bilateral C-2 fracture had completely fused (Fig. 5 ), indicating resolution of the patient's injury and success of the surgery.

\section{Discussion}

Hangman's fractures of the second cervical vertebra were first described by Schneider in $1965 .{ }^{18}$ While the name is derived from the characteristic cervical spine damage obtained by victims of execution by hanging, ${ }^{17}$ in the modern day hangman's fractures are typically associated with motor vehicle accidents and vertical trauma such as diving accidents. The mechanics of the injury primarily involve hyperextension and axial loading of the neck leading to fractures bilaterally in the pars interarticularis of C-2.

Due to the large size of the spinal canal at the upper cervical level, neurological compromise in patients who have sustained such injuries is rare. These patients most commonly present with severe, unyielding neck pain. A large majority of hangman's fractures resolve with external immobilization using a collar and halo vest for 8-14 weeks. ${ }^{4,20}$ However, severe, unstable cases with significant subluxation and angulation of C-2, such as in our patient, require surgical fusion. ${ }^{8}$

In elderly people, $\mathrm{C}-2$ fractures often result from falls, but that does not appear to be the cause in our patient. Giv-

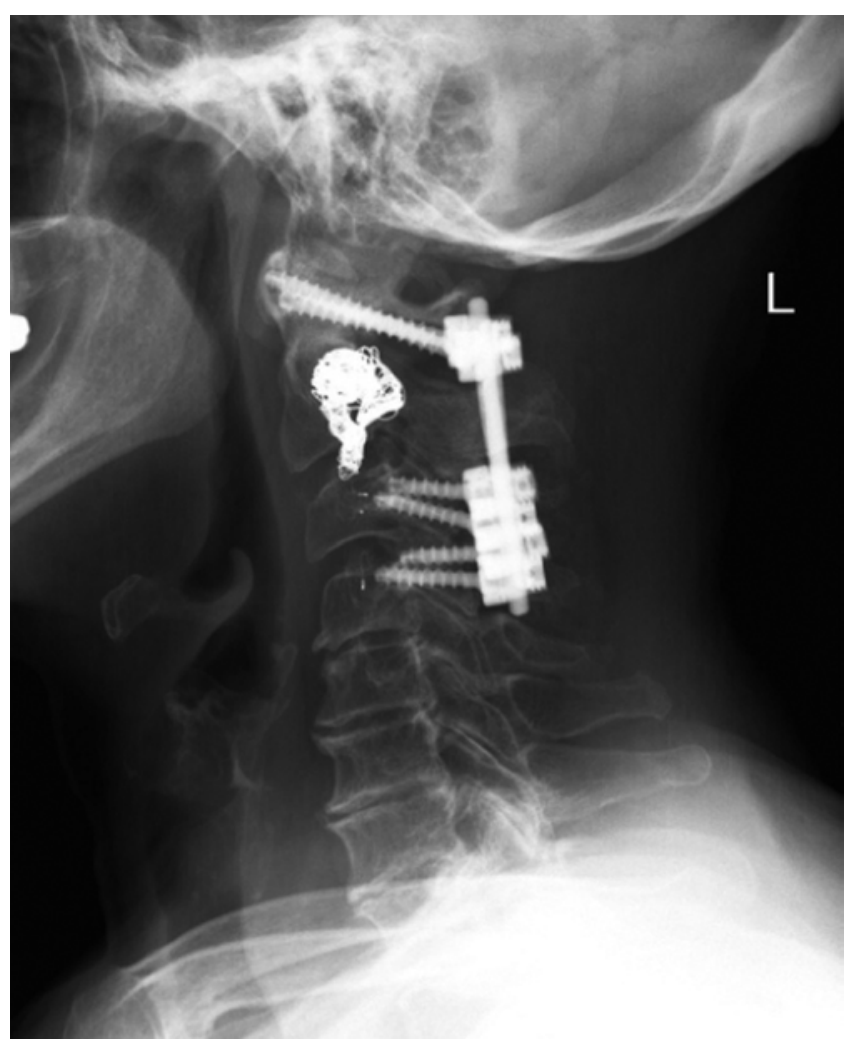

FIG. 4. Postoperative sagittal plain radiograph of the cervical spine showing the construct stabilizing the fracture without $\mathrm{C}-2$ screws. The coil embolization material is visible at the level of C-2.

en that she did not experience any significant trauma with the onset of her neck pain, it is possible that the fracture was incited by the erosive nature of the patient's complex AVF from the left VA.

Pathologic fractures are conventionally associated with neoplastic processes such as primary bone tumors or metastatic disease. Instances of fractures caused by vascular lesions are rare in the literature. To our knowledge, the only report of a pathologic fracture secondary to a vascular malformation was the 1980 article by Mnaymneh and colleagues, who described a fracture of the clavicle due to an arteriovenous malformation derived from the axillary artery.$^{13}$ Brooks et al. described a series of 3 patients who exhibited erosion of spinal vertebrae caused by various vascular lesions. ${ }^{2}$ In all 3 cases, the characteristic finding on plain radiographs was enlargement of the intervertebral foramina. There have also been reports of erosion of cervical vertebrae due to a tortuous VA..$^{1,19}$ While these cases do not demonstrate vertebral fracture, they confirm the ability of vascular irregularities to erode adjacent bone. It then follows that if such a process continues, the bone may weaken enough for it to fracture in the absence of trauma.

The precise pathophysiology behind the osseous erosion caused by large vascular lesions has not been studied to a great extent due to the rarity of this finding. It is presumed that because AVFs are high-flow and high-pressure systems, they may apply a chronic, pulsatile pressure to the surrounding bone. This theory is further supported by 


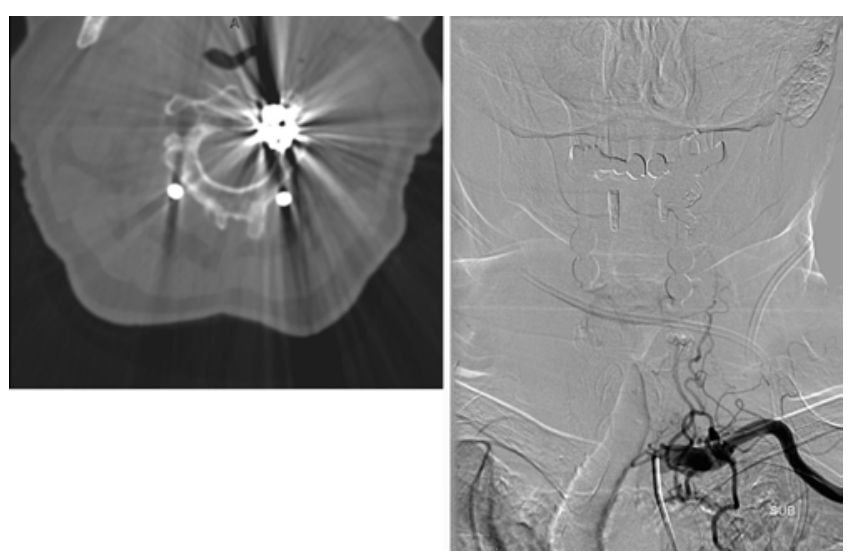

FIG. 5. Follow-up studies performed 6 months after surgery. Left: CT image demonstrating complete fusion of the bilateral C-2 fractures. Right: Angiogram of the left subclavian artery showing hypoplasia of the proximal left VA and stable occlusion of the distal VA. There is no obvious remnant of the AVF.

the fact that direct AVFs have a low incidence of hemorrhage and can be present for decades before causing any symptoms. ${ }^{15}$ This patient's initial CT scan demonstrated widening of the left transverse foramen along with preservation of the bony cortex consistent with an externally compressive force. This force, in combination with intrinsic osteoporotic weakening of the bone due to advanced age, was sufficient to convert a chronic process into an acute one requiring intervention.

Furthermore, cervical spine MRI demonstrated radiographic differences in the left C-2 fracture in comparison with that of the right side. The fracture on the left side showed signs of remodeling, whereas the right side showed marked STIR (short T1 inversion recovery) signal representing a more acute inflammatory process. ${ }^{6}$ These imaging findings suggest that the large AVF gradually weakened the C-2 vertebra on the left side leading to fracture of the left C-2 pars initially. Subsequently, excess axial load and extension force was redistributed to the right side of $\mathrm{C}-2$ resulting in a more acute fracture of the right pars.

It is worth noting that damage to the VA can be caused by cervical spine fractures and is also a known complication of surgery in the region..$^{9,10,11,16,21}$ However, in this case, given the complexity of the AVF and widening of the transverse foramen, it is likely that the fistula predated the fracture.

\section{Conclusions}

Hangman's fractures are typically a result of significant trauma to the cervical spine. However, when encountering such injuries in the absence of trauma, it is important to evaluate the patient for alternative causes. In this case, the culprit was a large cervical AVF identified by angiography after the observation of a suspiciously widened left transverse foramen on the initial cervical CT scan. In addition, this case highlights the rare ability of high-pressure AVFs to exert chronic compressive, and in this instance destructive, force on adjacent structures.
To the best of our knowledge, this is the first report of a spinal AVF presenting as a pathologic fracture of a cervical vertebra. It is likely that several predisposing factors contributed to this rare occurrence, such as the complexity and size of the fistula, the patient's age and sex being associated with poor bone health, and the chronicity of the fistula, which was likely present for many years.

\section{References}

1. Anderson RE, Shealy CN: Cervical pedicle erosion and rootlet compression caused by a tortuous vertebral artery. Radiology 96:537-538, 1970

2. Brooks BS, El Gammal T, Beveridge WD: Erosion of vertebral pedicles by unusual vascular causes. Report of three cases. Neuroradiology 23:107-112, 1982

3. Chen CJ, Saulle D, Fu KM, Smith JS, Shaffrey CI: Dysphagia following combined anterior-posterior cervical spine surgeries. J Neurosurg Spine 19:279-287, 2013

4. Coric D, Wilson JA, Kelly DL Jr: Treatment of traumatic spondylolisthesis of the axis with nonrigid immobilization: a review of 64 cases. J Neurosurg 85:550-554, 1996

5. Dailey AT, Hart D, Finn MA, Schmidt MH, Apfelbaum RI: Anterior fixation of odontoid fractures in an elderly population. J Neurosurg Spine 12:1-8, 2010

6. Golfieri R, Baddeley H, Pringle JS, Souhami R: The role of the STIR sequence in magnetic resonance imaging examination of bone tumours. Br J Radiol 63:251-256, 1990

7. Greenberg MS: Handbook of Neurosurgery, ed 7. New York: Thieme, 2010, Vol 1, pp 959-963

8. Greene KA, Dickman CA, Marciano FF, Drabier JB, Hadley $\mathrm{MN}$, Sonntag VK: Acute axis fractures. Analysis of management and outcome in 340 consecutive cases. Spine (Phila Pa 1976) 22:1843-1852, 1997

9. Hayes P, Gerlock AJ Jr, Cobb CA: Cervical spine trauma: a cause of vertebral artery injury. J Trauma 20:904-905, 1980

10. Huttman D, Cyriac M, Yu W, O'Brien JR: The unusual presentation of a vascular injury after lumbar microdiscectomy: case report. J Neurosurg Spine 24:381-384, 2016

11. Jeanneret B, Magerl F, Stanisic M: Thrombosis of the vertebral artery. A rare complication following traumatic spondylolisthesis of the second cervical vertebra. Spine (Phila Pa 1976) 11:179-182, 1986

12. Lee MJ, Bazaz R, Furey CG, Yoo J: Risk factors for dysphagia after anterior cervical spine surgery: a two-year prospective cohort study. Spine J 7:141-147, 2007

13. Mnaymneh W, Vargas A, Kaplan J: Pathologic fracture of the clavicle caused by arteriovenous malformation. Clin Orthop Relat Res (148):256-258, 1980

14. Mulligan RP, Friedman JA, Mahabir RC: A nationwide review of the associations among cervical spine injuries, head injuries, and facial fractures. J Trauma 68:587-592, 2010

15. Muralidharan R, Saladino A, Lanzino G, Atkinson JL, Rabinstein AA: The clinical and radiological presentation of spinal dural arteriovenous fistula. Spine (Phila Pa 1976) 36:E1641-E1647, 2011

16. Pelker RR, Dorfman GS: Fracture of the axis associated with vertebral artery injury. A case report. Spine (Phila Pa 1976) 11:621-623, 1986

17. Rayes M, Mittal M, Rengachary SS, Mittal S: Hangman's fracture: a historical and biomechanical perspective. J Neurosurg Spine 14:198-208, 2011

18. Schneider RC, Livingston KE, Cave AJ, Hamilton G: "Hangman's fracture" of the cervical spine. J Neurosurg 22:141154,1965

19. Slover WP, Kiley RF: Cervical vertebral erosion caused by tortuous vertebral artery. Radiology 84:112-114, 1965 
20. Sonntag VK, Hadley MN: Nonoperative management of cervical spine injuries. Clin Neurosurg 34:630-649, 1988

21. Takahashi T, Tominaga T, Ezura M, Sato K, Yoshimoto T: Intraoperative angiography to prevent vertebral artery injury during reduction of a dislocated hangman fracture. Case report. J Neurosurg 97 (3 Suppl):355-358, 2002

22. Torbert JT, Lackman RD: Pathologic fractures, in Pignolo RJ, Keenan MA, Hebela NM (eds): Fractures in the Elderly: A Guide to Practical Management. New York: Humana Press, 2011, pp 43-53

23. Vasudevan K, Grossberg JA, Spader HS, Torabi R, Oyelese AA: Age increases the risk of immediate postoperative dysphagia and pneumonia after odontoid screw fixation. Clin Neurol Neurosurg 126:185-189, 2014

\section{Disclosures}

The authors report no conflict of interest concerning the materi- als or methods used in this study or the findings specified in this paper.

\section{Author Contributions}

Conception and design: Pacione, Sen. Acquisition of data:

Pacione, Riina. Analysis and interpretation of data: Pacione, Sen. Drafting the article: Pacione, Sen. Critically revising the article: Pacione, Sen, Benjamin. Reviewed submitted version of manuscript: all authors. Approved the final version of the manuscript on behalf of all authors: Pacione. Administrative/technical/material support: Pacione. Study supervision: Pacione.

\section{Correspondence}

Donato Pacione, New York University School of Medicine, 530 1st Ave., Ste. 8R, New York, NY 10016. email: donato.pacione@ nyumc.org. 